\title{
Alexandre De Gusmão (1695-1753) e a tributação das minas do Brasil
}

\author{
Sezinando Luiz Menezes*
}

Resumo: O artigo tem por objetivo analisar a política tributária de Portugal para as regiões mineradoras do Brasil ao longo da primeira metade do século XVIII. Naquele período, o poder da Coroa se fez mais presente na América portuguesa. Tal crescimento pode ser explicado, por um lado, a partir da maior complexidade que a própria monarquia adquire ao longo da época moderna, e, por outro, em razão do desenvolvimento de novas atividades produtivas da colônia. No Brasil, o aspecto mais visível do crescimento da presença do Estado vincula-se à política tributária e fiscal e, nesse sentido, Alexandre de Gusmão teve um papel de destaque, propondo uma reforma tributária que substituía a multiplicidade de impostos existentes por uma "capitação".

Palavras-chave: Instituições coloniais, mineração, reforma tributária.

Não se constitui uma novidade afirmar que a história - enquanto desenrolar dos acontecimentos - pertence ao passado. No entanto, a eleição dos temas da história, isto é, a construção historiográfica, é sempre resultado de opções do historiador. Opções estas que, evidentemente, são condicionadas pela historicidade do próprio analista. Ou seja, se o fato pertence ao passado, a forma de abordá-lo, o enfoque, é sempre contemporânea ao estudioso.

Sendo assim, em uma época em que as discussões em torno do tamanho e das atribuições do Estado estão entre as mais candentes, aumenta o interesse pelo papel que a monarquia portuguesa teria desempenhado, utilizando os termos de Jorge Couto (1995), na construção do Brasil.

Nesse trabalho será analisada a discussão em torno da tributação das minas do Brasil em um momento em que a mineração se torna uma das principais atividades produtivas da colônia, a primeira metade do século XVIII, e, nessa discussão, sobressai-se a participação de Alexandre de Gusmão.

Alexandre de Gusmão, conhecedor de várias línguas, estudioso de matemática, mecânica e filosofia experimental, é considerado um dos cinco maiores mercantilistas portugueses (Amzalak, 1928, p.25). Nascido em Santos-SP, em 1695, realiza seus primeiros estudos no Seminário de Belém (Bahia). Por volta de 1708, com 14 anos, foi para Portugal, onde iniciou seus estudos de cânones em Coimbra. Esses estudos foram interrompidos em 1714, quando embarcou para a França como secretário do Conde de Ribeira Grande (embaixador português). Enquanto esteve em Paris, a escolla do Universo, 
conforme chamou-lhe um contemporâneo (Almeida, 1983), Gusmão estudou direito na Sorbonne, onde leu Descartes, Spinosa, Newton e Locke e abriu uma casa de jogos, embora a legislação francesa proibisse esta atividade a estrangeiros (Cortesão, 1952a, p.200).

Gusmão regressou a Portugal em 1719, para, no ano seguinte, ser enviado em missão diplomática à Itália, onde permaneceu até 1728. Em Roma, "trabalhou durante 7 anos em melhorar o faustoso guarda-roupa da capela real” (ibidem, p.256). Quando retornou a Portugal, tornou-se secretário do Rei (a princípio secretário particular, depois secretário de estado). Aproximadamente em 1731 passou a ter um papel de destaque na condução da política exterior do Reino. No ano seguinte foi eleito membro da Academia Real de História e passou a gozar de certo prestígio literário.

Em 1733, Alexandre de Gusmão propôs uma nova forma de tributação, o sistema de capitação dos escravos, em substituição ao quinto do ouro das minas. Segundo Cortesão, a elaboração dessa proposta foi um marco na vida de Gusmão. A partir de então, sobretudo entre os anos de 1735 e 1737, cresceu sua influência junto ao Rei e ele tornou-se "o principal inspirador e definidor da política exterior de Portugal, a que deu novos rumos e que teve por finalidade máxima o reconhecimento da expansão territorial e traçado dos limites do Brasil" (ibidem, 1952a).

Neste período escreveu a maior parte de seus trabalhos. Além de traduções, onde se destaca a adaptação para o português da farsa de Molière, Georges Dandin, sob o título O marido confundido, Gusmão escreve uma vastíssima obra, que compreende:

... correspondência oficial, oficiosa ou familiar: memórias políticas e geográficas; ensaios sobre economia política, crítica literária, costumes sociais, e até sobre uma nova ortografia da língua portuguesa, discursos acadêmicos e panegericos; libretos de ópera, poemas, a coleção dos seus pareceres como conselheiro do Conselho Ultramarino ou como assessor de D. João V; e, finalmente, as suas minutas de leis, portarias, alvarás, bulas, cartas e ordens régias de toda a sorte, e, acima de tudo, instruções e correspondência diplomática sobre atos ou tratados em negociações com a Santa Sé, a Espanha, a França e a Grã-Bretanha. (ibidem, p.9)

Entre 1740 e 1743, num período chamado por Jaime Cortesão de "eclipse parcial", teve seu poder diminuído e passou a dividir sua influência junto ao Rei com o Cardeal da Mota e o jesuíta italiano Carbone.

Em 1741, escreveu os Apontamentos políticos históricos e cronológicos sobre as fábricas do Reino e os Apontamentos discursivos sobre o dever impedir-se a extração da 
nossa moeda para fora e Reinos estrangeiros, por causa da ruína que daí se segue. Nesses trabalhos, Gusmão aponta quais são, a partir de sua perspectiva, os principais problemas socioeconômicos vividos por Portugal e, sobretudo, que medidas deviam ser tomadas para solucioná-los.

Em 1743, foi nomeado conselheiro do Conselho Ultramarino, onde teve uma atuação destacada. Teve também uma ativa participação em quase todos os atos importantes do governo luso em relação ao Brasil entre 1731 e 1750. Além da mencionada questão da tributação da região mineradora, destaca-se a sua preocupação com a defesa das ocupações portuguesas na América. Nesse sentido, Gusmão promoveu a imigração de casais açorianos para ocupar o sul do Brasil, para onde enviou especialistas em determinação de longitudes.

Homem de sua época, ao mesmo tempo em que redigiu a lei pragmática (1749), que proibia "o luxo e o excesso de trajes, carruagens, móveis, lutos e outros abusos de ostentação exterior", mantinha o gosto pelo luxo. "As manufaturas portuguesas pareciamlhe rudes. E nada o satisfazia, em matéria de suntuária, como os produtos franceses" (ibidem, p.422-3).

Já no final de sua vida, em 1750, Alexandre de Gusmão foi o principal negociador português do Tratado de Madrid. Com a morte de D. João V nesse mesmo ano, em grande parte devido às divergências com o futuro Marquês de Pombal, caiu no ostracismo. Além da oposição do futuro marquês à forma como o Tratado de Madrid havia sido negociado pois Sebastião José de Carvalho e Melo não concordava com a cessão da Colônia de Sacramento aos espanhóis -, as divergências com relação à política econômica e às disputas internas pelo poder no ocaso do Reinado de D. João V afastaram Gusmão das esferas políticas (Azevedo, 1990, p.78). Em 31 de dezembro de 1753, isolado, sem prestígio e financeiramente arruinado, cheio de dívidas, veio a falecer ${ }^{1}$.

As atividades que mais envolveram Gusmão ao longo de sua vida pública vinculam-se à manutenção e defesa da colônia portuguesa na América, o Brasil. Tais atividades culminaram no mencionado tratado que, embora tenha sido posteriormente anulado, foi de extrema importância. Sua execução conduziu ao massacre das missões jesuítas, no episódio conhecido como "guerra guaranítica" (1754-1756), e definiu o perfil fronteiriço do sul do Brasil que, com alterações, mantém-se até nossos dias.

Em sua luta pela manutenção dos domínios portugueses na América, inclui-se a discussão e os encaminhamentos em torno da mineração. A atividade mineradora é tratada 
por ele a partir de dois enfoques distintos: o de homem de estado e o de "mercantilista". Dessa primeira abordagem trataremos a seguir.

A descoberta de ouro no interior do Brasil deu novo alento ao combalido império colonial português. É justamente, mas não apenas, a descoberta e início da produção aurífera na América portuguesa que passou a exigir maior presença do Estado português e um aprimoramento da organização administrativa e política no Brasil (Eglésias, 1974). Essa necessidade pode ser observada em um parecer do Conde de Assumar sobre o projeto de capitação apresentado por Alexandre de Gusmão. No parecer o autor afirmar que

cuidavaõ antigamente os mineiros que estavaõ tam bem cituados nas suas Montanhas, que naõ podia subir a ellas, nem o poder, nem a justiça real; deste erro já estaõ dezenganados e de dezobedientes, e revoltozos, se tornaraõ cordeiros. (Assumar, 1953, p.503)

Aliada a esse fato, a crescente complexidade que a organização do Estado moderno adquire ao longo dos séculos XVI ao XVIII exige gastos cada vez mais vultosos. O Estado moderno necessita de recursos para a defesa e a guerra, para a burocracia estatal, para a diplomacia, para a justiça, para a polícia, para a manutenção de vias de transporte. Além disso, destaca-se ainda a necessidade de amparo aos órfãos, aos inválidos e aos pobres, etc.

No caso específico de Portugal, devem ser mencionados também os gastos públicos com a manutenção da corte - Rei, Nobreza e criados ${ }^{2}$ - e os gastos com a Igreja, uma vez que, em Portugal, as despesas da Igreja eram responsabilidade do Estado. Finalmente, destacam-se ainda as despesas com a manutenção e administração do, ainda vasto, império colonial.

Para fazer frente às crescentes despesas, o Estado português depende dos impostos cobrados tanto no Reino - onde somente o $3^{\circ}$ estado é tributado - quanto no mundo colonial.

À medida que a expansão ultramarina adquire importância econômica, as atividades a ela relacionadas também vão gradativamente tornando-se mais importantes como fontes de tributação. Assim sendo, ao redor de 1520, "as receitas fiscais captadas no trato d'além-mar já ultrapassavam de um terço os tributos e taxas recolhidos na metrópole pelo Erário Régio" (Alencastro, 1998). Entre os impostos usualmente cobrados pela Coroa, eram comuns os quintos e a capitação, as tarifas de importação e exportação e os impostos sobre a transmissão de propriedade (sisa), sendo que este último era cobrado sobre toda e qualquer transação, inclusive transações comerciais (Holanda, 1993). 
Na época da Restauração, a necessidade de aumentar os recursos do Estado, inclusive para enfrentar a Espanha e a Holanda - que havia invadido o nordeste brasileiro , fez que as cortes fossem convocadas para discutir aumentos na tributação.

No Reino, o aumento da carga tributária não foi bem recebido e surgiram manifestações em contrário, dentre as quais se destaca o Sermão de Santo Antonio pregado pelo Padre Antonio Vieira (1959), na capela Real, em Lisboa, em 14 de setembro de 1642, às vésperas da reunião das cortes.

Na colônia, além dos impostos sobre a transmissão de propriedade, importações e exportações, destacavam-se os dízimos - antigo tributo eclesiástico, cedido, nas conquistas portuguesas, à Ordem de Cristo (Prado Junior, 1987; Souza, 1982), ordem da qual o Rei de Portugal era Grão-mestre - e os quintos. Estes dois últimos eram tributos fixados diretamente sobre a produção - respectivamente $10 \%$ e $20 \%$ - e deveriam ser pagos in natura, forma de pagamento nem sempre respeitada pelos contratadores, que normalmente preferiam receber em moeda. Assim, o dízimo já era cobrado, por exemplo, sobre o açúcar e a pecuária. Além destes tributos

\begin{abstract}
seguiam-se os direitos de alfândega; as passagens dos rios e registros (alfândegas secas); as entradas (em Minas Gerais); imposições especiais sobre bestas que vinham do Sul e se cobravam em Sorocaba (São Paulo). Havia ainda os donativos, terças partes e novos direitos, que se pagavam pelas serventias dos ofícios de justiça (escrivães, meirinhos, solicitadores, etc.); bem como emolumentos de provisões e patentes (nomeações para cargos públicos). Além destes tributos ordinários, ... os subsídios extraordinários, que se estabeleciam de vez em quando para atender à emergência do Estado.(Prado Junior, 1987, p.321)
\end{abstract}

Normalmente, a arrecadação era realizada pelos contratadores, particulares a quem a coroa arrendava, mediante contrato, os direitos de arrecadação tributária por um determinado período de tempo.

Assim, a presença mais efetiva e uma maior intervenção do Estado português na colônia visavam, fundamentalmente, aumentar a arrecadação tributária, organizar a vida social e incrementar a produção. Neste sentido, em 1700, por exemplo, foram enviados para a América quatro mestres mineiros numa tentativa de estimular a produtividade da mineração a partir da introdução de novas técnicas ${ }^{3}$.

Um outro aspecto importante dos esforços da coroa foi a reforma na legislação sobre a mineração. A antiga legislação, que remontava aos séculos XVI e XVII ${ }^{4}$, não apenas se revelava arcaica para a nova realidade da produção aurífera brasileira, mas, 
sobretudo, era completamente ignorada na colônia.

Em resposta às novas demandas, a partir de 19 de abril de 1702, um novo Regimento passou a regulamentar a mineração no Brasil e, diferentemente do que fora até então praticado, a tributação sobre a produção aurífera passou a ser recolhida pela própria coroa. Dessa forma, já em 1700, foram nomeados provedores especiais para cobrar o quinto do ouro que havia sido estabelecido pelo código de exploração mineira de 1557 e permanece em vigor até 1835 (Hanson, 1986, p.194). Contudo, o grande volume de ouro contrabandeado fez que a coroa buscasse alternativas que inibissem os descaminhos.

Em 1710, surgiram os primeiros projetos para a criação das casas de fundição, onde o ouro deveria ser quintado, e que, no entanto, não se tornaram, naquele momento, realidade. Em 1713, além do quinto, os mineradores foram obrigados a pagar, como tributo extraordinário, uma finta anual de trinta arrobas que foi reduzida, em 1718, para vinte e cinco arrobas. Como a questão da sonegação permanecesse preocupante, em 1725 a coroa acaba com a finta e institui, finalmente, as casas de fundição. A solução provocou reação contrária por parte dos mineiros e o Conde das Galveias, Governador das minas, pressionado, reduziu, pelo bando de 25 de maio de 1730 , o quinto de $20 \%$ para $12 \%$.

O Rei, por seu lado, não aprovou tal medida e ordenou que o quinto fosse restabelecido, através da ordem Régia de 24 de abril de 1733. Com a elevação da taxa, provavelmente devido a um aumento dos descaminhos, a arrecadação diminuiu. Sob a taxa de $12 \%$, a arrecadação havia atingido o seu ponto máximo, caindo, contudo, com o retorno da taxa de $20 \%$. Era necessário, como afirmava, em seu parecer, em 1733, o Conde de Assumar,

... advertir que o Estado prezente das Minas, necessita deste, ou de outro promptissimo remedio, porque na forma em ,q se achaõ, naõ pode ser mais deploravel para a fazenda de Sua Mag. ${ }^{\text {de }}$, nem mais perigoza p. $^{\text {a }}$ os vassalos: a primeira padese pelas fraudes, e latrocinios, os segundos pelos sustos, e pelas pennas a que ficaõ expostos, de que foy, e serâ sempre origem a caza da fundiçaõ, e da moeda. (in Cortesão, 1953, parte V, p.502)

Nesse contexto, Alexandre de Gusmão propôs uma reforma na tributação que, essencialmente, substituía a multiplicidade de impostos existentes, inclusive o quinto, por apenas dois: a capitação - a ser cobrada sobre o número de escravos - e o maneio ou censo que incidiria "sobre a indústria dos homens livres".

Segundo o projeto de Gusmão, o imposto deveria incidir sobre todos os escravos 
maiores de 15 anos, inclusive aqueles que eram utilizados em atividades distintas da mineração, incluindo-se os escravos domésticos, as mulheres e os velhos ${ }^{6}$, pois, "por muitas considerações, que facilmente ocorrerão ao leitor de nenhuma sorte convem que se deixe izento da matricula escravo algum de idade habil para o trabalho" (Gusmão, in Cortesão, 1952, p.69).

Ao defender a reforma da tributação, Gusmão usava os mais distintos argumentos. Entre estes se destacam as facilidades para a cobrança do novo imposto e a maior dificuldade de sonegação decorrente do sistema de capitação. Para Gusmão, quanto mais simples o sistema tributário, melhor é sua arrecadação, pois diminui a necessidade de funcionários, a possibilidade de corrupção e de sonegação:

Mostra a Razão e a experiencia, que em cobranças mui vastas, como são as da Fazenda Real, quanto mais abreviado e facil é o systhema de executal-as mais proveito sae ao Principe e mais suave aos vassalos. He mais util para o Principe, porque lhe poupa os caminhos de ser roubado, e multiplicidade de exactores, e o desasocego que causa uma arrecadação, a qual por muitas vias poder ser defraudada. (Gusmão, in: Cortesão, 1952, p.57)

Além disso, para Gusmão, a capitação possibilitaria maior facilidade de fiscalização e controle, pois, "viria a ser por este methodo tanto mais certa e real a arrecadação quando vae de tributar o Povo por cousas que póde esconder, ou por outras que lhe ficará sendo impossível encubrir" (Gusmão, in Cortesão, 1952c, p.57).

Com a capitação, o povo também seria beneficiado, pois, o novo imposto

he também mais suave para o povo, que fica isento de concussões de huma turba de ministros e das opressões, a que estão necessariamente expostos os innocentos pelos remedios que para evitar os descaminhos escogita o Governo contra o Reos. (Gusmão, in Cortesão, 1952, p.57)

Outro argumento utilizado por Gusmão era as maiores possibilidades de desenvolvimento do comércio,

Viria também a florescer muito mais o commercio daquellas partes, e o contentamento dos habitadores, pela liberdade total do seu negocio, pela maior barateza dos generos e pelo socego de ficarem livres de todos os tributos com uma só imposição. (Gusmão, in Cortesão, 1952, p.58)

Assim sendo, Gusmão demonstrava que a mudança da tributação seria vantajosa, 
tanto para o Estado quanto para o contribuinte.

Com relação à produção de diamantes, Gusmão fazia uma proposta que extrapolava o terreno da política fiscal. Para aqueles que trabalhavam na prospecção de diamantes, ele também propunha a capitação e o maneio, no entanto as taxas deveriam ser mais elevadas. Explicava por que:

Tudo bem ponderado o unico meio de por os diamantes em reputação, e de utilizar com elles a Fazenda Real, e o commercio do Reino, he o da Capitação dos escravos, mas experimentando-se ainda com elle o inconveniente da vileza, a que se tem reduzido este genero, e os descaminhos, de que agora fazem menção as ultimas cartas das Minas, he preciso aperfeiçoal-o, dando melhor providencia, do que se deu até o presente a estes tres pontos. Primeiro a forma de arrecadar o tributo da capitação. Segundo a quantia, de que deve ser este tributo, e o maneio, que tambem se deve introduzir para observar a igualdade. Terceiro a sahida de tam grande numero de diamantes, que já tem vindo, e sobre tudo dos que se estão esperando pela frota da Bahia, que ainda hade acumular-se muito mais ao retorno desta, que está a sahir para o Rio ...

Passando ao segundo ponto explicarei a razão porque ponho tão alto os preços da Capitação, e maneio. A grande baixa, que tem dado os diamantes, provem do excessivo numero, dos que já vem vindo; nenhum outro remedio parece, que pode ter mais, que augmentando-se o tributo a tal excesso, que sem prohibir expressamente a extração, venha a produzir o mesmo effeito, affugentando os Mineiros, pela probabilidade de não tirarem das pedras o que baste para ficarem cobertos, do que lhes custar a capitação e maneio; com isto se conseguirá certamente não se extrahir mais, que alguma mui modica porção dellas, as quaes, assim pela raridade, como pela importancia do tributo, com que desde a sua origem vêm carregados, se venderão com boa reputação, pois que os Mineiros as não ham de querer dar com perda, e se lhes não acharem tal sahida, que os cubra da despesa, e deixe lucro desistirão de minerar. (Gusmão, in Cortesão, 1952, p.97-8)

A exploração de diamantes no Brasil havia aumentado a oferta dessa pedra no mercado mundial e, por conseguinte, reduzido seus preços. Neste caso, a política fiscal deveria ser utilizada como instrumento de intervenção na produção, aumentanto os custos, diminuindo a oferta e provocando um aumento dos preços no mercado, ou seja, valorizando a produção de diamantes no Brasil.

No entanto, devido à grande quantidade de diamantes já produzidos, isso não seria suficiente. Para valorizar os diamantes a Coroa deveria abarcar todos os diamantes já produzidos e que ainda não tivessem chegado ao Reino.

se se deixar pois a venda dos ditos diamantes ao arbitrio dos particulares não produzirá a augmentação do tributo o effeito de levantar-lhes o preço, sendo no progresso de tres ou quatro annos, isto é depois que não correrem já diamantes 
alguns, senão os que houverem sido extrahidos com o pezo do maior tributo, e entretanto é certo, que terá o Reino perdido muitos milhões, do que haverá podido lucrar.

Para acudir a tão relevante damno, não me ocorre mais seguro meio, que de abarcar todos os diamantes, que hão de vir pelos duas proximas frotas da Bahia, e Rio ... (GUSMÃO, in CORTESÃO, 1952, p.99).

Para levar avante sua proposta, Gusmão argumenta que, devido à ausência de "negociantes ricos" em Lisboa, a Fazenda Real seria obrigada a "abarcar" os diamantes “por sua conta”. No entanto, isso não seria um problema, ao contrário, a valorização dos diamantes decorrente dessa intervenção possibilitaria um lucro aos cofres públicos que não poderia ser de menos que cincoenta por cem em hum até dois annos (Gusmão, in Cortesão, 1952). A estratégia seria então a adoção de um valor de capitação flexível. Se, em um primeiro momento, ele deveria ser alto o suficiente para desalojar os mineiros, em um segundo momento, deveria ser baixo o suficiente para atrair novos mineradores:

que poucos ou nenhum Mineiros se atrevam a pagal-a, e conseguintemente fiquem quasi desamparadas as Minas do Serro; assim que se venha a restabelecer a estimação conveniente dos diamantes, a dita Capitação se deveria ir proporcionando cada anno ao numero da gente, que acudisse a extrahir diamantes (Gusmão, in Cortesão, 1952, p.100).

Finalmente a capitação foi colocada em prática e deve, naquele momento, ter contribuído para o aumento da arrecadação na região mineradora, mas não se manteve exatamente da forma planejada pelo autor da proposta. Ao contrário do que pretendia Alexandre de Gusmão, a introdução da capitação não aboliu os outros impostos anteriormente existentes ${ }^{7}$.

Após 16 anos a capitação foi suprimida e o quinto voltou a ser cobrado integralmente. A coroa estipulou uma quantidade mínima de ouro a ser recolhida - 100 arrobas por ano, compensável de 2 em 2 anos -, e, caso este mínimo não fosse atingido decretava-se a derrama. No momento em que isso ocorreu, Gusmão, partindo em defesa da capitação e tentando mostrar, mais uma vez, as vantagens desta forma de tributação, escreveu, em 19 de dezembro de 1750, os Reparos sobre a disposição da Lei de 3 de dezembro de 1750, a respeito do novo método da cobrança do quinto do ouro nas Minas Gerais, pelo qual se aboliu o da capitação (in Cortesão, 1952c, p.228-51). Neste documento Gusmão comparava as duas formas de tributação, concluindo pela superioridade da capitação sobre o quinto. 
Para Gusmão, se a capitação já se justificava na década de trinta, era, em 1750, mais necessária ainda. Nos anos trinta, a fiscalização era extremamente rigorosa, “chegando-se ao excesso de abrir as Cartas dos particulares" (Gusmão, in Cortesão, 1952, p.229); as penas aos contrabandistas eram mais rigorosas do que aquelas que estavam em vigor em 1750; além de poucas estradas, as dificuldades de acesso obstaculizavam os descaminhos e contribuíam, assim, para um aumento na arrecadação.

Em 1750, a multiplicidade de caminhos e as penas mais brandas aplicadas aos sonegadores e contrabandistas haviam tornado os descaminhos mais fáceis e atraentes. Assim "era preciso buscar um meio, para que o direito Real não estivesse fundado em uma cousa tão fácil de esconder, e extraviar, como o ouro" (Gusmão, in Cortesão, 1952, p.230). Perante tais facilidades, Gusmão pergunta:

He esperavel que haja quem voluntariamente vá privar-se da quinta parte do seu cabedal podendo salva-lo com pouco risco e trabalho? ... não haverá quem, podendo a seu salvo aproveitar a quinta parte do cabedal, vá por escrupulo entregalla ao Real Erario; sobretudo em um paiz, onde os eclesiasticos, para se justificarem do descaminho do ouro, tem semeado a pestifera doutrina de que a fraude dos quintos não pede restituição, por ter pena civil, quando chega a descobrir-se. (Gusmão, in Cortesão, 1952, p.232)

Assim, concluindo, Gusmão considera, mais uma vez, que o quinto é uma forma injusta de tributar:

Não duvido, que nas Minas fiquem contentissimos com esta Lei os Ecclesiasticos, os homens de Governança, os poderosos, os mercadores, e os comboieiroz, porque ainda que ella de direito os obriga ao Quinto, de facto, e na substancia lhe abre os caminhos para se isentarem do pagamento delle. Duvido porem que recebam o mesmo contentamento os pobres mineiros, quando virem (como veram brevemente) que pela lei ficam obrigados a pagar muito mais do que pagavam, e que ham de pagar os innocentes pelos culpados. (Gusmão, in Cortesão, 1952, p.228)

Além disso, o autor previa que, "pelo estravio do ouro", a derrama tornar-se-ia indispensável e, quando isso ocorresse, a insatisfação geraria grandes problemas. No entanto, naquele momento, Gusmão pouco ou quase nada podia fazer para interferir nas decisões da Coroa e, embora discordasse profundamente, não teve como manter a capitação. 


\section{REFERENCIAS BIBLIOGRÁFICAS:}

ALENCASTRO, Luiz Felipe de. No labirinto das colônias. In: Folha de S.Paulo, 17/05/98, caderno 5.

ALMEIDA, Luís Ferrand de. Alexandre de Gusmão em Paris: uma carta inédita (1716). In Revista portuguesa de História. Coimbra, 1983, t.XX.

AMZALAK, Moses Bensabat. Do estudo da evolução das doutrinas económicas em Portugal. Lisboa: Oficina Gráfica do Museu Comercial, 1928.

ANTONIL, André João. Cultura e opulência do Brasil. Belo Horizonte/São Paulo: Itatiaia/USP, 1982.

AZEVEDO, João Lúcio. O Marquês de Pombal e sua época. Lisboa: Clássica editora, 1990.

CORTESÃO, Jaime. Alexandre de Gusmão e o Tratado de Madrid (1695-1735). Rio de Janeiro: Ministério das Relações Exteriores/Instituto Rio Branco. 1952a. Tomo I, parte I.

Alexandre de Gusmão e o Tratado de Madrid (1695-1735). Rio de Janeiro:

Ministério das Relações Exteriores/Instituto Rio Branco. 1952b. Tomo II, parte I.

. Alexandre de Gusmão e o Tratado de Madrid (1750). Rio de Janeiro: Ministério das Relações Exteriores/Instituto Rio Branco, 1950. Tomo I, parte II.

. Alexandre de Gusmão e o Tratado de Madrid. Rio de Janeiro: Ministério das Relações Exteriores/Instituto Rio Branco, 1953. Parte V.

COUTO, Jorge. A construção do Brasil. Lisboa: Cosmos, 1995.

EGLÉSIAS, Francisco. Minas e a imposição do Estado no Brasil. In: Revista de História. São Paulo, n.100, p.257-73, 1974.

HANSON, Carl A. Economia e Sociedade no Portugal Barroco (1668-1703). Lisboa: Dom Quixote, 1986.

HOLANDA, Sérgio Buarque de (Dir.). História geral da civilização brasileira. Tomo I $7^{\mathrm{a}}$ edição. Rio de Janeiro: Bertrand Brasil, 1993. Vol. II, tomo I.

MAGALHÃES, José Calvet. História do Pensamento económico em Portugal (da Idade Média ao Mercantilismo). Coimbra, 1967.

SÉRGIO, Antonio (Org.). Antologia dos Economistas portugueses. Lisboa: Sá da Costa, 1974.

PRADO JUNIOR, Caio. Formação do Brasil contemporâneo. 20a. edição. São Paulo: 
Brasiliense, 1987.

SMITH, Adam. A Riqueza das Nações. São Paulo: Nova Cultural, 1986.

SOUZA, Laura de Melo e. Desclassificados do ouro. A pobreza mineira no século XVIII.

Rio de Janeiro: Ed. Graal, 1982.

VIEIRA, Padre Antonio. Sermões (obra completa). 2a . edição. Lisboa: Lello \& Irmão, 1959. Vol.VII.

ZAMELLA, Mafalda P. O abastecimento da capitania de Minas Gerais no século XVIII.

São Paulo: Hucitec/Edusp, 1990.

MENEZES, Sezinando Luiz. Alexandre de Gusmão (1695-1753) and the taxation of the mines of Brazil. História, São Paulo, v. 25, n. 2, p. 179-191, 2006.

Abstract: The objective of this article is to analyze the tributary politics in Portugal in relation to Brazil along the first half of the XVIII century. In that period, the monarchy power was stronger in Portuguese America. Such growth can be explained, on one hand, starting from the largest complexity that the monarchy acquires along the modern time, and, on the other hand, because of the development of colony's productive activities. In Brazil, the most visible aspect related to the State's presence growth is linked to the tributary politics and, in which Alexandre de Gusmão had a distinctive role proposing a tax reformation that could substitute the multiplicity of existent taxes for a "capitation".

Keyword: Colonial institutions, mining, tributary reformations.

Artigo recebido em 11/2006. Aprovado em 12/2006.

\section{NOTAS}

* Departamento de História, Universidade Estadual de Maringá.

1 "Por morte do estadista, tornou-se necessário, para o pagamento das suas dividas, vender em leilão judiciário, uma parte de seus bens" (Cortesão, 1952b, p.424).

${ }^{2}$ Embora o luxo, a ostentação, a suntuosidade tenham sido extremados em Portugal, há de se ressaltar que o luxo é um importante elemento presente nas mais variadas representações do Estado moderno, pois: "Uma Corte que empobrece ou se apresenta mais modestamente, é um soberano, e portanto um país, que perde prestígio, tanto internamente, quanto no plano internacional" (Holanda, 1993, p.341-2). A Relação da Embaixada do Conde da Ribeira junto de Luiz XIV e em que Alexandre de Gusmão serviu de secretário (in Cortesão, 1952b, t.II, parte I), mostra como o luxo era uma necessidade dos representantes do Estado moderno.

${ }^{3}$ Esta preocupação com o aumento da produtividade das minas pode ser observada no Regimento dado por D. João V a Martinho de Mendonça de Pina e Proença, quando este foi nomeado governador das Minas.

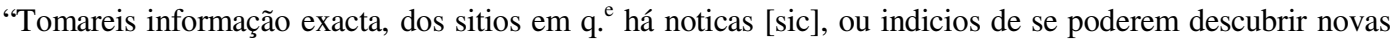
Minas de ouro ou pedras preciosas, e se com algua maquina, ou artificio, se podem facilitar as suas Lavras". Regimento dado por El Rei D. João V, mas escrito por Alexandre de Gusmão, ao novo Governador das Minas, Martinho de Mendonça de Pina e de Proença, com referências muito particulares ao sistema de capitação a inaugurar naquela capitania. 30 de outubro de 1733 (in Cortesão, 1952c, p.106).

${ }^{4}$ A mineração era regulada em Portugal pelo Regimento das terras minerais de 1608 e pelo Regimento de 
1618 (Holanda, 1993).

${ }^{5}$ A este respeito Gusmão afirma: "passado o anno de 1730, em que avultou o Ouro quintado a 12 por 100 , em razaõ de $\sim, q$ muytos dos que o tinhaõ reservado, e escondido, entendendo $\sim, \mathrm{q}$ a resolução do g. ${ }^{\text {or }}$ poderia brevem. $^{\text {te }}$ ser revogada por El Rey, quizeraõ aproveytarse da ocasiaõ favoravel; logo no anno seg. ${ }^{\text {te }}$ de 1731 se viu, que tornavaõ as couzas ao antigo estado, pois fazendo bem a conta ao que entrou na Caza da fundiçaõ em 16 mezes, e tiran do della 40 arrobas, ,q entraraõ em hum só dia, quando o Conde das Galveas publicou o bando dos 20 p. 100, consta que já nos annos de 1731 e de 1732, apezar dos 12 p. 100, haviaõ tornado as couzas â mesma bayxa em de q d'antes se achavam. GUSMÃO, Alexandre de. Resposta de Alexandre de Gusmão a vários pareceres e dúvidas sôbre o projeto da Capitação (1733) (in Cortesão, 1952c, p.111).

${ }^{6}$ A justificativa para a tributação sobre estes últimos é, no mínimo, curiosa. Diz Gusmão: “quem tiver escravo, que pela sua velhice lhe dão renda o que baste para cobrir o gasto do tributo, e deixar ganancia, ou o forra se o servio bem em moço, ou o venda pelo que poder fóra das minas, ou finalmente se tem gosto em conserval-o, pague por ele" (Gusmão, Projeto de capitação e maneio, proposto a D. João V por Alexandre de Gusmão, 1733, In Cortesão, 1953, p.63).

${ }^{7}$ A este respeito, no regimento dado por D. João V ao governador das minas, Martinho de Mendonça de Pina e de Proença, e escrito pelo próprio Gusmão, o rei afirma: "De todos os arbitrios, q. ${ }^{\mathrm{e}}$ tem occorrido parece o mais conveniente o de hua Capitação geral de todos os Escravos, e hua contribuição proporcional aos Lucros q. e se fazem nas Minaz, sem dependencia de Escravos, ficando os demais direytos antigos em seu vigor." Regimento dado por El Rei D. João V... 30 de outubro de 1733 (in Cortesão, 1952c, p.106). 